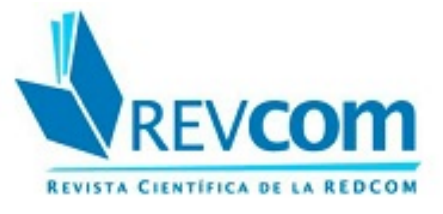

REVCOM. Revista científica de la red de carreras de Comunicación Social

ISSN: 2451-7836

redcom.revcom@gmail.com

Universidad Nacional de La Plata

Argentina

\title{
Apuntes sociolingüisticos sobre el lenguaje inclusivo
}

Sayago, Sebastián

Apuntes sociolingüisticos sobre el lenguaje inclusivo

REVCOM. Revista científica de la red de carreras de Comunicación Social, núm. 9, 2019

Universidad Nacional de La Plata, Argentina

DOI: https://doi.org/10.24215/24517836e015 


\section{Apuntes sociolingüisticos sobre el lenguaje inclusivo}

Notas sociolinguísticas do fenômeno chamada "linguagem inclusiva"

Sebastián Sayago

DOI: https://doi.org/10.24215/24517836e015

Universidad Nacional de la Patagonia San Juan Bosco

(UNPSJB), CONICET, Argentina

sayago.discurso@gmail.com

Recepción: 05 Octubre 2019

Aprobación: 15 Octubre 2019

\section{Resumen:}

Este artículo está estructurado en dos partes. En la primera, se plantea una aproximación sociolingüística al fenómeno denominado "lenguaje inclusivo". Allí se reflexiona acerca de la utilidad de la variante con e y se proponen cuatro criterios para el análisis (umbral, economía, habitus lingüístico y estrategia). En la segunda, se exponen criterios gramaticales que pueden ser útiles para una eventual estandarización de esta variante del español.

Palabras Clave: lenguaje inclusivo, sociolingüística, estilo, diversidad de género.

\section{Resumo:}

Este artigo está estruturado em duas partes. No primeiro, é proposta uma abordagem sociolinguística do fenômeno chamada "linguagem inclusiva". Aqui refletimos sobre a utilidade da variante com e e quatro critérios são propostos para a análise (limiar, economia, habitus linguístico e estratégia). No segundo, são expostos critérios gramaticais que podem ser úteis para uma possível padronização dessa variante do espanhol.

Palavras-Chave: linguagem inclusiva, sociolinguística, estilo, diversidade de gênero.

\section{INTRODUCCIÓN}

Antes de la emergencia de lo que se denomina lenguaje inclusivo, ya había sugerencias para utilizar el español tratando de incluir a las mujeres sin alterar las normas aceptadas por la Real Academia Española. Estas iniciativas pueden ser etiquetadas bajo el rótulo estilo inclusivo institucionalizado y vistas como parte de una comunicación políticamente correcta. Así, por ejemplo, se recomienda, si hay diversidad de género, hacer referencia a entidades abstractas y no a entidades concretas: en vez de decir los gerentes, se debería decir la gerencia; en vez de decir, los políticos, se debería decir la clase política. El problema es que, en muchas ocasiones, este uso resulta inadecuado. Si hay gerentes y gerentas jugando al golf, no es adecuado decir La gerencia está jugando al golf; si hay políticos y políticas que se retiran de una sala de deliberaciones, no es adecuado decir La clase política se retiró de la sala de deliberaciones. Se pueden dar muchísimos ejemplos de ese tipo.

En esta línea de incluir sin alterar la lengua, se suele optar también por las formas de masculino y femenino desarrolladas en la frase: todos y todas, argentinos y argentinas, vecinos y vecinas, etc. El principal inconveniente de esta opción es que resulta antieconómica: si en un texto hay muchas ocurrencias, es tan agotador producirlas como leerlas o escucharlas. Consideremos, por ejemplo, Los padres más preocupados y comprometidos y las madres más preocupadas y comprometidas con la educación se mostraron dispuestos $y$ dispuestas a colaborar.

La escritura ofrece alternativas más económicas y, por lo tanto, más fluidas. La más común es el uso de la barra (/) para explicitar la complementariedad de los morfemas de género masculino y femenino: todos/as, argentinos/as, vecinos/as, etc. Aún más económica, pero no avalada por la normativa de la RAE, es el uso de la x yla@: todxs, argentinxs,vecinxs, por un lado, yvecin@s, tod@s, argentin@s,vecin@s, por otro. Se crea un 
nuevo morfema de género: además de la $o$ (masculino) y la $a$ (femenino), se habilita la xo la @ como morfema de género no marcado o género por defecto. El problema de esta modalidad es que no se puede trasladar a la oralidad, por lo tanto, no resuelve el problema de la referencia a la diversidad de género. Es más, este límite del pasaje de lo escrito a la oralidad exhibe una imposibilidad.

La propuesta del uso de la e, en cambio, permite resolver la brecha entre oralidad y escritura, a la vez que es una opción económica y fluida. El costo es alto: a diferencia de lo que ocurre con la barra, la x y el @, el uso de esta vocal como morfema de género obliga a realizar un cambio gramatical que afecta a todo el sistema de la lengua. ${ }^{1}$ Y esa es una de las principales razones de la controversia.

A continuación, propondré algunas vías de acceso para entender la complejidad de este problema y, luego, me centraré en sus aspectos más lingüísticos.

\section{EL NUEVO LENGUAJE INCLUSIVO}

La propuesta del nuevo lenguaje inclusivo puede ser analizada a partir del supuesto de que el lenguaje refleja y (re)produce la realidad. Por un lado, describe el mundo (las entidades, procesos y relaciones de orden físico y simbólico); por otro, contribuye a la creación y al mantenimiento del mundo.

Esta facultad del lenguaje es bastante evidente en el nivel léxico, donde se realiza la mayor innovación lingüística. Pensemos, por ejemplo, en el neologismo femicidio: describe un hecho específico y, a la vez, lo establece en la realidad, lo diferencia de otros hechos similares en algún aspecto e impone nuevos modos de hablar acerca de los asesinatos cometidos contra mujeres. Y sus efectos trascienden el campo del significado referencial y alcanzan el ámbito más amplio de la cultura.

Sin caer en determinismos, se puede aceptar que hay una relación entre la variedad léxica y la percepción de la realidad. Al incorporar la palabra femicidio, se reconoce socialmente la situación de asesinato de una mujer en un contexto de violencia de género y se asumen todos los supuestos implicados. En este caso particular, el uso del término suele generar una reflexión ideológica y metalingüística que resulta en la aceptación o el rechazo de la expresión (hay personas que están a favor del uso de esta palabra y personas que están en contra -cada vez menos, afortunadamente). Pero no ocurre así con otros neologismos. Al empezar a oír y decir términos como Internet, Whatsapp, googlear, notebook, celular, youtuber, influencer, no experimentamos la misma propensión a analizar su trasfondo ideológico (pese a que son consecuencia de un claro imperalismo cultural y económico).

La expresión lenguaje inclusivo es una frase (un sintagma nominal, para ser más precisos o precises) que también suele despertar reflexiones ideológicas y metalingüísticas y, además, fuertes posiciones encontradas. Hay quienes apoyan la iniciativa y quienes se horrorizan. Sin el respaldo de ningún estudio, podría asegurar que la mención y, sobre todo, el uso del lenguaje inclusivo despiertan más reacciones positivas y negativas que hablar del FMI, la deuda externa o la pobreza. Es interesante que algo que parece tan etéreo como la lengua desate tales pasiones.

\section{Cuestión de umbral}

La lengua diferencia para referir. Así, la oración El gato está sobre el felpudo implica la operación cognitiva y semántica de diferenciar entidades (el gato y el felpudo) y situaciones (el gato puede estar sobre el felpudo, bajo el felpudo, lejos del felpudo). La lengua convencionaliza diferencias que tienen importancia social. Se puede pensar en un umbral de relevancia: cuando algo lo supera, interviene la lengua para diferenciar y referir. Ese umbral, por supuesto, es histórico y cultural.

Si distinguimos con nombres el vacuno macho del vacuno hembra (toro y vaca, respectivamente) y no la llama macho de la llama hembra es porque la primera diferencia superó el umbral de relevancia y la segunda, 
no. La distinción es impulsada por necesidades comunicativas, de otro modo se generarían infinitas categorías socialmente insignificantes y, por eso, no utilizadas. No es un asunto de posibilidades lógicas sino de utilidad social. Dicho de otro modo, si la lengua distingue algo es porque eso importa.

Ahora bien, lo que pone en escena el lenguaje inclusivo es la necesidad (y el deber, que es su contracara) de que la lengua establezca una nueva diferencia. Eso es lo que está en discusión. Hay quienes afirman que, en este punto de la historia, no es posible continuar ignorando la diversidad de género y seguir tomando el masculino como la forma no marcada (es decir, como la forma por defecto para hacer referencia la diversidad) y, en la vereda de enfrente, están quienes consideran que esa diferencia no es suficientemente relevante como para modificar el sistema de género de la lengua. Para unes, ya se superó el umbral de relevancia; para otros, no. Y la diferencia es política en un sentido profundo: si la lengua es un bien común y si se puede modificar para que reconozca un hecho que objetivamente existe, ¿por qué no hacerlo? ¿Quién tiene la autoridad para aceptarlo o rechazarlo? ¿Quién decide si algo está arriba o debajo del umbral de relevancia?

\section{Cuestión de economía}

Unas de las leyes que regulan el uso y la evolución de la lengua es la ley del menor esfuerzo. Esta se manifiesta con gran evidencia en el plano fonético, ya que tendemos a simplificar los movimientos articulatorios. Por ejemplo, para pronunciar la palabra examen, decimos /egsamen $/{ }^{2}$ y no /eksamen/, una disminución del esfuerzo de fonación que también está presente (aunque exagerado) en la producción considerada propia del uso vulgar /esamen/ o en la no pronunciación de la /s/ de final de palabra y en la sustitución de /s/ por una aspiración, como en /nosotro/ o /nosotroh/, respectivamente. La historia de la lengua está repleta de casos exitosos de economía (del latín apothēca derivó bodega, de farina, harina, etc.).

Los alcances de esta ley del menor esfuerzo son discutibles en el plano sintáctico y en el semántico, donde interviene la observación de otros principios, tales como el de orden, el de claridad y el de brevedad o síntesis. El cumplimiento de estos puede estar reñido con la idea del menor esfuerzo, por lo que conviene representarnos la relación como algo variable: unas veces, logramos economizar esfuerzos en la producción del mensaje y, a la vez, somos ordenados, claros y breves (p.e., cuando respondemos $S i$, voy a tu casa); otras veces, es más difícil economizar esfuerzos y cumplir con esos principios (p.e., para responder a la pregunta ¿Qué relación hay entre capitalismo y democracia?).

El rechazo del lenguaje inclusivo supone una tensión entre la ley del menor esfuerzo y el principio de claridad o de precisión. Modificar el sistema de género para ser más transparentes a la diversidad de género supone un gran esfuerzo. Es mucho más fácil adoptar cambios léxicos que cambios gramaticales, porque el sistema gramatical opera en el uso con muy poco grado de reflexión. Puedo darme cuenta de las palabras que estoy utilizando y reflexionar sobre alguna expresión particular, pero es más mucho más difícil darme cuenta de la flexión de los sustantivos y verbos, de los mecanismos para asignar casos o de las concordancias sintácticas. Ese es un conocimiento que se tiene y se usa, pero, comúnmente, no se hace explícito.

El lenguaje inclusivo exige un gran esfuerzo tanto de parte de los hablantes/escritores como de los oyentes/ lectores, sobre todo en esta etapa, en la que todavía no hay manuales de estilos y son los hablantes quienes tienen que decidir cómo establecer las concordancias. Más adelante, retomaremos este tema y propondremos algunas soluciones para los casos más problemáticos. Concluiremos en este punto afirmando que una de las razones del rechazo es el carácter antieconómico de la reforma del sistema gramatical que supone el lenguaje inclusivo. 


\section{Cuestión de habitus lingüistico}

Relacionada con las dos cuestiones anteriores, está la de la (in)seguridad del hablante, la confianza que este tiene acerca de su capital lingüístico y, en términos más generales, de los valores relativos del mercado lingüístico (lo que está bien y lo que está mal, lo que se debe respetar y tomar como modelo y lo que se debe rechazar y corregir). Desde esta perspectiva, el lenguaje inclusivo es un capital subversivo, asociado principalmente a un grupo de jóvenes de clase media, con militancia social. Cuestiona la pauta de prestigio en ámbitos públicos (instituciones educativas, medios de comunicación, asambleas, etc.).

En estrecha vinculación con la (in)seguridad lingüística, está el aspecto del gusto. El lenguaje inclusivo desafía el oído, multiplica la frecuencia de la $e$ y, como no estamos acostumbrados, a muchas personas les resulta gracioso, hasta ridículo. No es un asunto gramatical, no es un asunto de sistema, es algo más irracional: extrañamiento. Pero, aunque irracional, no es un aspecto menor. Los griegos áticos se burlaban de los extranjeros cuyas lenguas les sonaban como bar-bar-bar y, por eso, los llamaron barbaroi (bárbaros). Tengamos en cuenta que, para la RAE, un barbarismo es "una incorrección lingüística que consiste en pronunciar o escribir mal palabras, o en emplear vocablos impropios” (primera acepción en la actual versión online). Por lo tanto, todes, alumnes y egresades son barbarismos.

El habitus lingüístico es producido por el mercado lingüístico y tiende a reproducirlo. Quien posee un capital legítimo tiende a resistirse a un cambio en la distribución de valores y, por supuesto, de prestigio. Quien posee un capital que es ilegítimo en el marco de un mercado lingüístico unificado tiende a continuar respetando la pauta de prestigio que ha determinado la subvaloración de su propio capital (es decir, lo han convencido de cuál es la pauta correcta: no la domina, pero la admira). En ambos casos, se produce un rechazo a la innovación.

¿Cómo se puede caracterizar el grupo innovador desde una perspectiva sociolingüística? Para que el ejercicio del lenguaje inclusivo sea exitoso, los hablantes deben poseer el capital lingüístico legítimo (la lengua estándar, con sus diferentes registros) y una conciencia metalingüística suficientemente desarrollada como para poder ejecutar los ajustes gramaticales que correspondan. Como apunta Bourdieu para explicar las revoluciones científicas, las estrategias de subversión exitosas solo pueden ser realizadas por los más ricos (lingüisticamente) entre los recién llegados.

\section{Cuestión de perseverancia y estrategia}

Se puede asumir que todas las personas que lo defienden adhieren también a luchas por el respeto a la diversidad de género, pero también que esta relación no es necesariamente inversa: no todas las personas que adhieren a las luchas por el respeto a la diversidad de género adhieren al lenguaje inclusivo. En algunos casos, el rechazo de este es parte del rechazo a la militancia social de quienes lo impulsan y, más en el fondo, el rechazo al cuestionamiento de la cultura patriarcal.

¿El lenguaje inclusivo se impondrá finalmente como una variante aceptada del español? Aunque la respuesta que se dé inevitablemente esté sesgada por el punto de vista (y los deseos) de quien la responda, todos deben asumir que, si se consolida y se extiende o si se debilita y desaparece, dependerá de muchos factores, la mayoría de ellos extralingüísticos. Para que triunfe, los grupos que lo defienden deberían llevar adelante dos acciones fundamentales. La primera es plantear el lenguaje inclusivo como un estilo y no como una lengua. En este sentido, la denominación lenguaje inclusivo sugiere que el cambio en el sistema de género producirá un nuevo lenguaje o una nueva lengua (un nuevo español). Eso supondría un cambio absoluto y obligatorio, algo que es imposible. Si, en cambio, se define el lenguaje inclusivo como un estilo, sería una variante del español, una opción más dentro del repertorio disponible para los hablantes. 
Un estilo puede ser opcional u obligatorio en ciertos contextos o en ciertos géneros discursivos y la opcionalidad/obligatoriedad puede ser implícita o explícita. Con el fin de no provocar rechazos, convendría que sea propuesto como un estilo opcional: nadie está obligado a usarlo y quien lo use debe ser respetado.

La segunda acción es avanzar en la estandarización del estilo, ya que, como apuntamos, un cambio en el género es muy complejo porque impacta en la morfología de sustantivos, adjetivos y pronombres. Para ello, se deberían consensuar (dentro lo que es posible) y adoptar criterios que puedan ser expuestos en manuales.

\section{CRITERIOS GRAMATICALES PARA UN ESTILO INCLUSIVO: UNA PROPUESTA}

Siguiendo a Murillo (1999), asumimos que los procedimientos lingüísticos más comunes para expresar la diferencia de sexo en los nombres son dos: la moción y la heteronimia.

-La moción: cambio o alargamiento de la terminación para expresar el femenino.

$$
\begin{aligned}
& \text { perro - perra } \\
& \text { gallo - gallina } \\
& \text { héroe - heroína } \\
& \text { emperador - emperatriz } \\
& \text { sacerdote - sacerdotisa }
\end{aligned}
$$

La heteronimia: uso de palabras o raíces diferentes.

$$
\begin{aligned}
& \text { toro - vaca } \\
& \text { hombre - mujer } \\
& \text { padre - madre }
\end{aligned}
$$

Hay otros casos en los que, a pesar de la diferencia biológica en cuanto al sexo, gramaticalmente no queda evidenciada la variación. Esto ocurre con los nombres llamados comunes, en los que la única forma de distinción es la sintáctica, es decir, agregando los artículos o adjetivos respectivos:

el astronauta - la astronauta

el periodista - la periodista

el estudiante - la estudiante

el testigo - la testigo

El conflicto se produce frente a dos posibilidades: a) referir mediante el uso de un sustantivo común o un pronombre a una persona de género no especificado (alguien que puede tener género masculino, femenino $\mathrm{u}$ otro) y b) referir mediante un sustantivo común o un pronombre a un conjunto de dos o más personas con variedad de género.

Hasta ahora, de manera aproblemática, se ha utilizado el género masculino como género no marcado, es decir, como género inespecífico, de alcance totalizador: en singular, Día del Estudiante; en plural, reunión depadres.

En lo que sigue, desarrollaré algunos criterios gramaticales de uso del estilo inclusivo y centraremos la atención en usos que presentan dificultades.

\section{Fórmulas de destinación}

Este es el uso más simple y extendido. Las fórmulas de destinación pueden ser frases conformadas por adjetivo + sustantivo o solo por un sustantivo. Veamos el paradigma completo: 


\begin{tabular}{|l|l|l|}
\hline & Singular & Plural \\
\hline Femenino & $\begin{array}{l}\text { Estimada } \\
\text { alumna }\end{array}$ & $\begin{array}{l}\text { Estimadas } \\
\text { alumnas }\end{array}$ \\
\hline Masculino & $\begin{array}{l}\text { Estimado } \\
\text { alumno }\end{array}$ & $\begin{array}{l}\text { Estimados } \\
\text { alumnos }\end{array}$ \\
\hline Inclusivo & $\begin{array}{l}\text { Estimade } \\
\text { alumne }\end{array}$ & $\begin{array}{l}\text { Estimades } \\
\text { alumnes }\end{array}$ \\
\hline
\end{tabular}

La opción Estimade alumne (o una similar) debería ser la que se use por defecto para dirigirse de manera individualizada a una persona cuyo género se desconoce o una persona con identidad de género no binaria (es decir, que no puede ser clasificada como masculina ni femenina).

\section{Pronombres personales}

\begin{tabular}{|l|l|l|}
\hline & Singular & Plural \\
\hline $\begin{array}{l}1^{\circ} \\
\text { persona }\end{array}$ & Yo & $\begin{array}{l}\text { Nosotros / } \\
\text { Nosotras / } \\
\text { Nosotres }\end{array}$ \\
\hline $\begin{array}{l}2^{\circ} \\
\text { persona }\end{array}$ & Vos / Usted / Tú & $\begin{array}{l}\text { Ustedes / } \\
\text { Vosotros - } \\
\text { vosotras - } \\
\text { vosotres }\end{array}$ \\
\hline $\begin{array}{l}3^{\circ} \\
\text { persona }\end{array}$ & Él / Ella / Elle & $\begin{array}{l}\text { Ellos / Ellas / } \\
\text { Elles }\end{array}$ \\
\hline
\end{tabular}

Como ocurre con la expresión de destinación en singular, el pronombre elle debería ser usado cuando se desconoce el género o cuando se trata de alguien con identidad no binaria.

\section{Pronombres demostrativos}

\begin{tabular}{|l|l|l|}
\hline & Singular & Plural \\
\hline Femenino & $\begin{array}{l}\text { esta/esa/aquella } \\
\text { diputada }\end{array}$ & $\begin{array}{l}\text { estas/esas/aquellas } \\
\text { diputadas }\end{array}$ \\
\hline Masculino & $\begin{array}{l}\text { este/ese/aquel } \\
\text { diputado }\end{array}$ & $\begin{array}{l}\text { estos/esos/aquellos } \\
\text { diputados }\end{array}$ \\
\hline Inclusivo & $\begin{array}{l}\text { este/ese/aquelle } \\
\text { diputade }\end{array}$ & $\begin{array}{l}\text { estes/eses/aquelles } \\
\text { diputades }\end{array}$ \\
\hline
\end{tabular}

\section{Pronombres indefinidos}

\begin{tabular}{|l|l|l|}
\hline & Singular & Plural \\
\hline Femenino & una/alguna & unas/algunas/todas \\
\hline Masculino & un(o)/algún & unos/algunos/todos \\
\hline Inclusivo & une/algune & unes/algunes/todes \\
\hline
\end{tabular}




\section{Pronombres con caso nominativo}

Estos pronombres cumplen el rol de sujeto gramatical, concuerdan en número con el verbo. Son los pronombres personales ya vistos, ahora en relación sintáctica de sujeto-verbo:

\begin{tabular}{|l|l|l|}
\hline & Singular & Plural \\
\hline Femenino & Ella canta & Ellos cantan \\
\hline Masculino & Él canta & Ellas cantan \\
\hline Inclusivo & Elle canta & Elles cantan \\
\hline
\end{tabular}

\section{Pronombre con caso acusativo}

Estas formas pronominales actúan como complemento obligatorio del verbo. Están ecnabezadas por la preposición $a$. Pueden ir acompañadas de un clítico $(l a, l o, l e)$ que refuerza la indicación de que la entidad referida es afectada por la acción realizada por el sujeto:

\begin{tabular}{|l|l|l|}
\hline & Singular & Plural \\
\hline Femenino & $\begin{array}{l}\text { María la agasajó a } \\
\text { ella }\end{array}$ & $\begin{array}{l}\text { María las agasajó a } \\
\text { ellas }\end{array}$ \\
\hline Masculino & María lo agasajó a él & $\begin{array}{l}\text { María los agasajó a } \\
\text { ellos }\end{array}$ \\
\hline Inclusivo & $\begin{array}{l}\text { María le agasajó a } \\
\text { elle }\end{array}$ & $\begin{array}{l}\text { María les agasajó a } \\
\text { elles }\end{array}$ \\
\hline
\end{tabular}

\section{Pronombres con caso dativo}

Estos pronombres refieren al receptor, que es encabezado por las preposiciones a y para. En el primer caso, se utiliza un clítico (nos, les) que no sufre variación respecto de las formas gramaticalizadas:

María nos envió una nota a nosotros / María nos envió una nota a nosotres

María les envió una nota a los docentes / María les envió una nota a les docentes

María envió una nota para nosotros / María envió una nota para nosotres

María envió una nota para los docentes / María envió una nota para les docentes

\section{Dificultades léxicas}

Ahora exploraremos un terreno más inestable que el de los pronombres: el de las categorías léxicas. Revisaremos siete casos.

a. Inexistencia de alternancia de género en el sustantivo, con morfema de género no marcado o. Ocurre con nombres que solo admiten la o del masculino y la variación es indicada con el artículo que los modifica. Por ejemplo: el miembro/la miembro. La variante inclusiva podría limitarse al uso del artículo le (le miembro) o podría modificar también el sustantivo (le miembre).

b. Inexistencia de alternancia de género en sustantivos y adjetivos terminados en -ente, -ante, -iente y -en. Es un caso similar al anterior, aunque aquí la variación queda restringida al artículo:

los inteligentes / las inteligentes / les inteligentes

los estudiantes / las estudiantes / les estudiantes 
los dirigentes / las dirigentes / les dirigentes

los cantantes / las cantantes / les cantantes

los parientes / las parientes / les parientes

los jóvenes / las jóvenes / les jóvenes

c. Incongruencia con las excepciones a la regla anterior. Hay sustantivos terminados en -ente que admiten variación de género mediante la variación con -a:presidente/presidenta, sirviente/sirvienta. Una solución, para contribuir a la regularidad de la lengua (algo que por motivos económicos y pedagógicos siempre es deseable), sería dejar de utilizar la forma con a para la referencia al femenino y utilizar solo los artículos para indicar la variedad: el presidente/la presidente/le presidente. Otra posibilidad es conservar la variante con morfema de género a y utilizar las formas con e para indicar masculino y género no marcado: el presidente/la presidental le presidente.

d. Inexistencia de alternancia de género en el sustantivo, con morfema de género no marcado a. Ocurre con palabras como: activista, dentista, oculista, futbolista. La solución más simple es conservar la forma del sustantivo y continuar señalando la variación de género con el artículo: el activista/la activista/le activista.

e. Palabras con morfema de género masculino e. Por ejemplo: nene/nena y pibe/piba. Siguiendo una solución propuesta anteriormente y teniendo en cuenta que resultaría muy difícil abandonar las formas con morfema femenino a, lo más conveniente sería adicionar el artículo le para indicar género no marcado: el nene/la nena/ le nene.

f. Complementación de o y a con e y modificación morfológica del sustantivo. Esta sería la posibilidad más creativa y, por eso mismo, la más resistida. Al haber variación en o y en a, habría que incorporar la e como morfema de género no marcado: un médico polémico/una médica polémica/une médique polemique, dos médicos polémicos/dos médicas polémicas, dos mediques polémiques.

g. Inexistencia de palabra para señalar la diversidad de género. La palabra padres puede incluir un conjunto integrado solo por hombres o uno integrado con diversidad de género. No hay una palabra que incluya padres y madres (como parents, en inglés) y, siguiendo la regla androcéntrica, el español utiliza la forma padres para incluir a las madres. Se podría crear un neologismo, una palabra con una raíz léxica distinta (ni padr-ni madr-) para constituir la referencia de género no marcado, pero es una opción demasiado complicada. Una solución más simple es referir a un grupo constituido por padres y madres utilizando indistintamente padres o madres, acompañados por el artículo les para indicar diversidad de género. Así, tendríamos: los padres/las madres/les padres $=$ les madres.

\section{UNA LENGUA PARA TODES}

No es forzado plantear el asunto desde la tensión entre justicia y orden. Si asumimos que es justo (éticamente correcto) reflejar con mayor precisión la diversidad de género, ¿por qué no hacerlo? ¿Para defender el supuesto orden de la lengua?

Me incluyo dentro del grupo de lingüistas que ve con entusiasmo y con interés teórico este fenómeno. Claramente, es un cambio inducido por una minoría (por motivos políticos) y no un cambio invisible adoptado por la masa hablante (sin motivos políticos). Su éxito no detendrá la violencia de género ni acabará con el machismo, pero agregaría un matiz muy productivo en la concepción de lengua/lenguaje y en la conciencia sociolingüística de los hablantes, incrementando la sensibilidad a la variedad de género.

El cambio ya está en marcha. Lo experimentamos, por ejemplo, cuando decimos todos (y todas) y no todes o cuando decimos todes, sabiendo que algune de nuestres receptores puede objetar la elección. 


\section{REFERENCIAS}

Murillo, J. (1999). La marcación de género en los sustantivos del español: entre la flexión y la derivación. Filología y Lingüistica, $X X V(1)$ : pp. 181-192.

\section{Notas}

1 Vale aclarar que el uso de la e no está unificado, lo que es comprensible. Hay grupos que la utilizan no para incluir hombres + mujeres sino para referir a personas con identidades de género no binarias, como en la secuencia: "Todos, todas y todes". Aquí seguiremos la opción inclusiva que vincula la e a cualquier diversidad de género.

2 Las barras indican que el vocablo está expresado en escritura fonológica, es decir, una transcripción que representa los fonemas (sonidos de la lengua) que efectivamente pronunciamos. 